\title{
LRIG1 expression and colorectal cancer prognosis
}

\author{
Maryam Bakherad ${ }^{1}$, Mahdieh Salimi ${ }^{2 *}$ (0, Seyed Abdolhamid Angaji ${ }^{1}$, Frouzandeh Mahjoubi ${ }^{2}$ \\ and Tayebeh Majidizadeh ${ }^{2}$
}

\begin{abstract}
Background: To make the right treatment decisions about colorectal cancer (CRC) patients reliable predictive and prognostic data are needed. However, in many cases this data is not enough. Some studies suggest that LRIGI gene (leucine-rich repeats and immunoglobulin-like domains 1) has prognostic implications in different kinds of cancers.

Methods: One hundred and two patients with colorectal cancer were retrospectively analyzed for LRIG1 expression at both mRNA and protein levels. SYBR Green Real-Time RT-PCR technique was used for mRNA expression analyses and Glyceraldehyde-3-Phosphate Dehydrogenase gene (GAPDH) was considered as a reference gene for data normalization. LRIG1 protein expression was analyzed using Immunohistochemistry. Additionally, appropriate statistic analyses were used to assess the expression of $L R I G 1$ in test and control groups. The prognostic significance of LRIG1 expression was analyzed using the univariate and multivariate analyses.
\end{abstract}

Results: The data revealed that the expression of $L R I G 1$ in both mRNA and protein levels was down regulated in colorectal tumor tissues $(P<0.01)$ but is not clinically relevant prognostic indicator in $C R C$.

Conclusions: Therefore, it is suggested that $L R I G 1$ expression analyses may not be considered as an important issue when making informed and individualized clinical decisions regarding the management of colorectal cancer patients.

Keywords: Prognostic indicator, Colorectal cancer, CRC, LRIG1, Gene expression

\section{Background}

Colorectal Cancer (CRC) is considered as one of the most significant cancers worldwide, with about 1 million new cases and more than 550,000 deaths per year [1]. Despite the significant advances in the diagnosis of CRC, the survival rate decreases for patients diagnosed with metastatic and regional disease [2]. The reported overall median survival time of CRC is only 1.1 years [3]; therefore, understanding about biological factors with impact on CRC is very important.

The lack of predictive and prognostic biomarkers with the ability to predict therapy response and recurrence

\footnotetext{
*Correspondence: salimi@nigeb.ac.ir

${ }^{2}$ Department of Medical Biotechnology, National Institute of Genetic

Engineering and Biotechnology (NIGEB), Tehran, Iran

Full list of author information is available at the end of the article
}

of the disease is an important issue that needs to be addressed. The LRIG1 (the leucine-rich repeats and immunoglobulin-like domains 1) as an emerging tumor suppressor and its paralogs LRIG2 (the leucine-rich repeats and immunoglobulin-like domains 2) and LRIG3 (the leucine-rich repeats and immunoglobulin-like domains 3), are considered to have prognostic significance in various kinds of cancers, such as head-and-neck $[4,5]$, prostate [6], breast $[7,8]$, uterine cervical cancer [9-11], and cutaneous squamous cell carcinoma [12], and glioma $[13,14]$.

The locus of LRIG1 is located on chromosome 3p14.3. The encoding protein is a transmembrane protein consisting of an extracellular region including three immunoglobulin (Ig)-like domains and fifteen leucinerich repeats. The leucine-rich repeats and immunoglobulin-like domains have interactions with all four

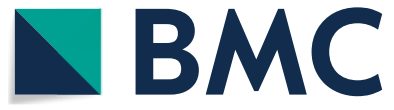

(c) The Author(s) 2021. Open Access This article is licensed under a Creative Commons Attribution 4.0 International License, which permits use, sharing, adaptation, distribution and reproduction in any medium or format, as long as you give appropriate credit to the original author(s) and the source, provide a link to the Creative Commons licence, and indicate if changes were made. The images or other third party material in this article are included in the article's Creative Commons licence, unless indicated otherwise in a credit line to the material. If material is not included in the article's Creative Commons licence and your intended use is not permitted by statutory regulation or exceeds the permitted use, you will need to obtain permission directly from the copyright holder. To view a copy of this licence, visit http://creativecommons.org/licenses/by/4.0/. The Creative Commons Public Domain Dedication waiver (http://creativeco mmons.org/publicdomain/zero/1.0/) applies to the data made available in this article, unless otherwise stated in a credit line to the data. 
extracellular region binding protein $B$ receptor family members leading to the regulation of receptor levels by subsequent lysosomal degradation and increasing ubiquitination, independent of ligands [15-17]. In addition the LRIG1 is considered as a marker of human epithelial stem cells in a quiescent non-proliferative state [18]. The enhanced proliferation associated with epithelial hyper-proliferation in vivo and stem cell expansion in vitro is the result of the genetic erosion of the leucine-rich repeats and immunoglobulin-like domains $[18,19]$. It is recommended by lineage tracing that the leucine-rich repeats and immunoglobulin-like domains mark non-cycling, long-lived stem cells of the 44 quiescent intestinal stem cell niche in the crypt [20]; and also progenitor cells in the stomach that are involved in restoring gastric cell mucosa after DMP-777 induced acute damage [21].

Although the LRIG1 plays vital role in cancers, little is known about its association with clinico-patho-physiology characteristics of CRC patients. Here the LRIG1 expression in the lesions of CRC patients was studied in order to evaluate its relationship with the major clinicohistological predictive factors and its respective impacts on patient prognosis hoping to improve the approaches for colorectal cancer management. Therefore, the main goal of the present study was to compare and analyze the expression levels of the LRIG1 gene in samples of tumor and normal colorectal tissues of CRC patients by quantitative real-time RT-PCR and immunohistochemical (IHC) techniques. Moreover, to estimate the prognostic indicator of the mentioned gene expression levels, we surveyed their correlations with clinicopathological parameters, as well as the overall survival (OS) of patients with CRC.

\section{Methods}

\section{Patient information}

A total of 102 cases of colorectal cancer from Imam Khomeini Hospital, Tehran, Iran were selected. The average age was $55.0 \pm 10.0$ years. The inclusion criteria were post-operative diagnosis of primary CRC based on histopathology. The study was approved by the Ethics Committee of the NIGEB based on the Helsinki declaration. All the patients signed informed consent. The ethics code number is IR.NIGEB.1395.11.10.E. The patients' characteristics are presented in Table 1. Overall survival (OS) was defined as the time from the date of primary treatment to the date of death from any cause or until the date of the last follow-up. Disease-free survival (DFS) for patients with CRC was defined as the time from the date of primary treatment to the date of diagnosis for recurrence or disease or to the date of the last follow-up.

\begin{tabular}{ll}
$\begin{array}{l}\text { Table } 1 \text { Baseline characteristics } \\
\text { patients }\end{array}$ & of \\
\hline Characteristic & Number (\%) \\
\hline Number of patients & $102(100)$ \\
Gender & \\
Male & $49(48)$ \\
Female & $53(52)$ \\
Age (years, mean \pm SD) & $55.00 \pm 10$ \\
Pathological stage & \\
Stage 1 & $27(26)$ \\
Stage 2 & $29(28)$ \\
Stage 3 & $24(24)$ \\
Stage 4 & $22(22)$ \\
Tumor size & \\
$<5 \mathrm{~cm}$ & $47(46)$ \\
$5-8 \mathrm{~cm}$ & $31(30)$ \\
$8-10 \mathrm{~cm}$ & $14(14)$ \\
$\geq 10 \mathrm{~cm}$ & $10(10)$ \\
Lymph nodes metastasis & \\
Positive & $49(48)$ \\
Negative & $53(52)$ \\
Other metastasis & $22(22)$ \\
\hline
\end{tabular}

\section{Immunohistochemical analysis}

Surgical specimens were formaldehyde fixed paraffin embedded and sectioned at a thickness of $4 \mu \mathrm{m}$ followed by xylene dewaxing, ethanol gradient rehydration and harnessed to high pressure and temperature for antigen retrieval. The slices were incubated in $\mathrm{H}_{2} \mathrm{O}_{2}$ harnessed to the primary antibody, rinsed with phosphate buffered saline (PBS), then harnessed to secondary and mouse anti-human LRIG1 monoclonal antibody, respectively. The slices incubated with PBS instead of the primary antibody were used as the negative control. The sections were assessed using an Olympus BX41 light microscope (Olympus, Tokyo, Japan) by a pathologist. The scale based on the reaction intensity were used to assess immunoreactivity in enterocytes or cancer cells of the studied sections $(0$, no reaction; 10 , up to $10 \%$; $30,11-30 \%$; 60 , 31-60\%; 80, 61-80\%; and 100, > 80\%) (Fig. 1).

\section{RNA extraction, cDNA synthesis and LRIG1 mRNA expression analysis}

Total RNA was isolated from the colorectal tissue using YTzol kit (Yekta Tajhiz Azma Co, Tehran, Iran) according to the manufacturer's protocol. cDNA was synthesized following the manufacturer's instructions (Cinaclon Co, Tehran, Iran) and stored at $-20{ }^{\circ} \mathrm{C}$ until analyzed. The primer sequences for glyceraldehyde3-phosphate dehydrogenase (GAPDH) and LRIG1 genes 

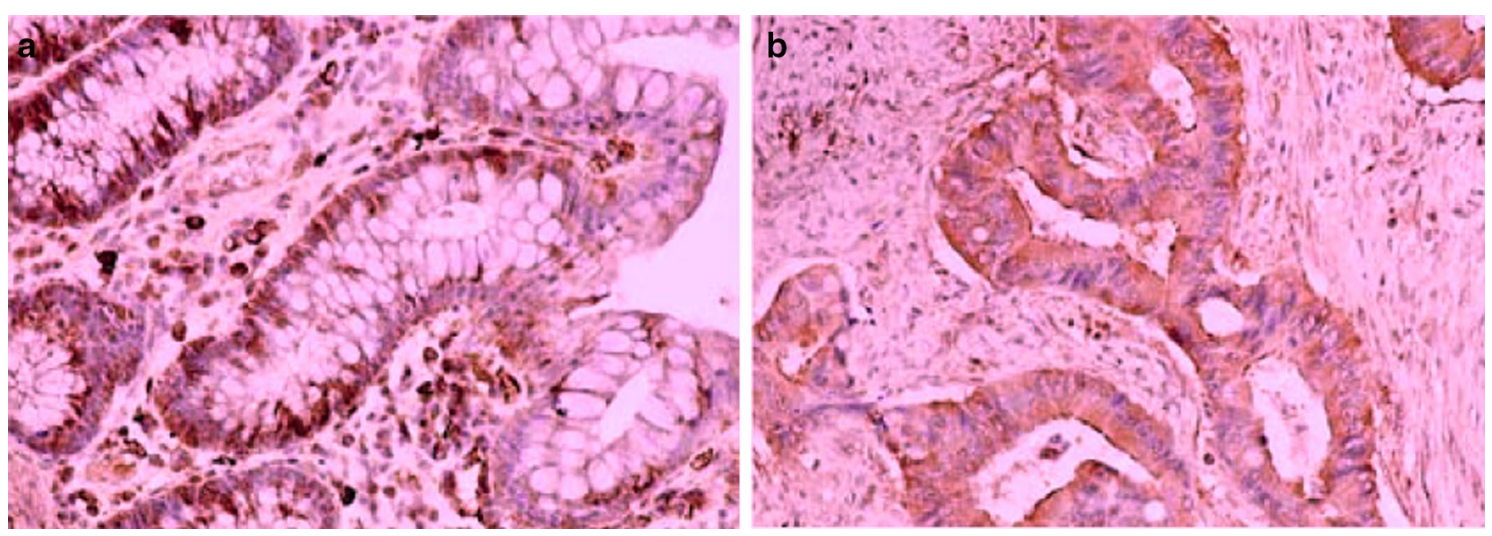

Fig. 1 Expression of $L R I G 1$ protein in colorectal cancer (CRC) and unchanged colon mucosa as assessed by immunohistochemistry. a Section of unchanged colon mucosa and $\mathbf{b}$ CRC show the immunoreactivity. Magnification, $\times 100$

Table 2 The primers for real-time quantitative reverse transcription PCR

\begin{tabular}{llll}
\hline Gene name & Primer sequence & $\begin{array}{l}\text { Product } \\
\text { size (bp) }\end{array}$ & $\begin{array}{l}\text { Annealing } \\
\text { temperature } \\
\left({ }^{\circ} \mathbf{C}\right)\end{array}$ \\
\hline LRIG1 & F: CTGCATGAGTTGGTCCTG & 112 & 60 \\
& TCC & & \\
R: TGTGGCTGATGGAATTGTG & & \\
GAPDH & F:GCAGGGGGGAGCAAAAG \\
& GGT & 219 & 60 \\
& R:TGGGTGGAGTGATGGCA & & \\
& TGG & & \\
&
\end{tabular}

LRIG1 leucine-rich repeats and immunoglobulin-like domain-1, GAPDH Glyceraldehyde-3-phosphate dehydrogenase

were designed using primer 3 software (https://prime r3.ut.ee/) and then blasted using https://www.ncbi. nlm.nih.gov/tools/primer-blast/. The designed primer sequences are shown in Table 2. The Real-time RT-PCR amplifications were conducted in a final volume of $15 \mu \mathrm{l}$ reaction mixture containing $1 \mu \mathrm{l}$ of cDNA, $7.5 \mu \mathrm{l}$ RealQ plus $2 \times$ master mix green (Ampliqon, Denmark), $0.6 \mu \mathrm{l}$ $(10 \mu \mathrm{mol} / \mathrm{l})$ of each primer and $5.3 \mu \mathrm{l}$ sterilized water, using the Rotor-Gene Q System (QIAGEN Hilden, Germany). The cycling conditions were as follows: 15 min at $95{ }^{\circ} \mathrm{C}$ followed by 40 cycles of denaturation at $95{ }^{\circ} \mathrm{C}$ for $30 \mathrm{~s}, 60{ }^{\circ} \mathrm{C}$ for $30 \mathrm{~s}$ and $72{ }^{\circ} \mathrm{C}$ for $30 \mathrm{~s}$ for the LRIG1 and also the GAPDH, which was used as a normalizer. Experiments were performed in triplicates for each data point. The linear standard curve (from 0.1 to $1000 \mathrm{ng}$ ) assessed by ultraviolet spectrophotometer was used for amplification efficiency determination of each primer pair. The standard curves showed good linearity and amplification (100\%). The data was presented as the fold change in gene expression normalized to an endogenous reference gene relative to the controls using $2^{-\Delta \Delta C T}$ method.

\section{Statistical analysis}

Graphpad Prism 8.0.2 (California Corporation, USA) and SAS computer software version 9.1 (SAS Institute Inc., Cary, NC, USA) were used to analyze the data. The Mann-Whitney $U$ test and Kruskal-Wallis test were performed for numerical data and the Chi-square test was used to analyze the relationship between parameter data. Numerical data are presented as the mean \pm standard deviation (SD). Differences were considered as statistically significant if $P<0.05$. The Cox proportional-hazards model was used for univariate and multivariate analyses to identify the independent prognostic factors for OS, DFS.

\section{Results \\ LRIG1 expression and clinicopathological features LRIG1 mRNA expression}

The LRIG1 mRNA expression was significantly downregulated in Colorectal cancerous tissues compared with normal control $(P<0.01)$. The mean of LRIG1 relative expression in cancerous tissues compared with normal control was $0.57 \pm 0.24$ with a range of 0.23 to 1.2 . About $40 \%$ of cancerous samples showed the relative expression $<0.5$ that was considered as downregulation. As shown in Fig. 2, there were no significant differences between different demographical and clinicopatological characteristics of CRC patients and LRIG1 expression $(P>0.05)$. 


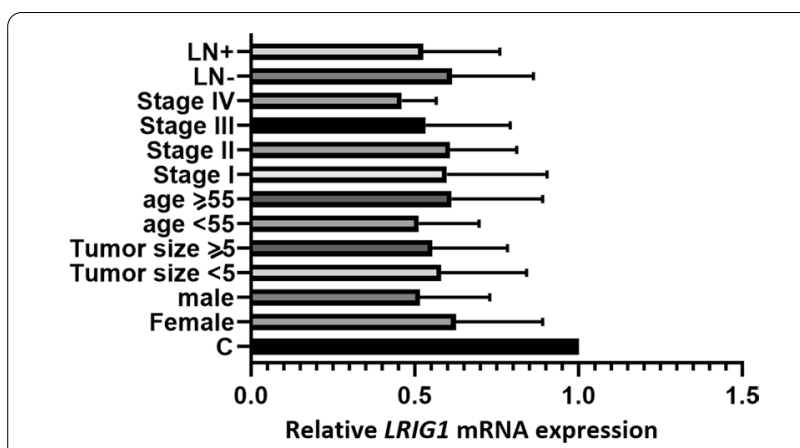

Fig. 2 Evaluation of the $L R / G 1$ relative mRNA expression in tumor tissues based on clinopathologic situations. LN lymph node metastasis, $C$ normal control

\section{LRIG1 protein expression}

The LRIG1 immunoreactivity was found in the cytoplasm of enterocytes as well as cancer cells of the analyzed tissues (Fig. 1).

The tumor LRIG1-positive rate in colorectal cancer tumors was $37.4 \%$, which was significantly lower than that in control tissues $(57.7 \%, P<0.05)$. There was no significant correlation in the expression of the LRIG1 with tumor size, tumor diameter, tumor differentiation, age, and the number of positive mesenteric lymph nodes or vascular cancer embolus $(P>0.05)$ (Table 3$)$.
Univariate and multivariable analyses of survival impact of LRIG1 expression in patients with CRC

The univariate and multivariate analyses were performed to investigate independent prognostic factors for Overall survival (OS) and Disease-free survival (DFS) in patients with colorectal cancer using the Cox proportional-hazards model (Table 4). The analysis results demonstrated no significant difference for parameters in terms of OS $(P>0.05)$ and DFS $(P>0.05)$.

\section{Discussion}

Cancer is one of the most important and prevalent diseases with poor prognosis and there is no effective method to treat and predict the procedure of tumorigenesis. Finding the appropriate biomarkers of cancer prediction or prognosis will have huge importance in cancer management. Nowadays the new strategies searching for informative biomarkers in cancer management have attracted good attention in the world. The increasing evidences have demonstrated the leucine-rich repeats and immunoglobulin-like domain as an independent prognosis factor and predictive biomarker of clinicopathology in variety of tumors. Due to inconsistency on the effect of the LRIG1 in different types of tumors, the present study was carried out to investigate the prognostic importance of the LRIG1 expression and its relationship with clinicopathological significance in CRC. In the present study, the expression of LRIG1 at both mRNA and

Table 3 Clinicopathological variables and their correlation with immunohistochemical expression of LRIG1 in primary tumors

\begin{tabular}{|c|c|c|c|c|}
\hline Clinicopathological variables & CRC patients $\mathrm{n}(\%)$ & Score < $30 \mathrm{n}(\%)$ & Score $\geq 30 \mathrm{n}(\%)$ & $P$ value \\
\hline \multicolumn{5}{|l|}{ Age } \\
\hline$\leq 57$ & $49(48)$ & $25(51.0)$ & $24(49.0)$ & \multirow[t]{2}{*}{0.451} \\
\hline$>57$ & $53(52)$ & $26(49.1)$ & $27(50.9)$ & \\
\hline \multicolumn{5}{|l|}{ Primary tumor location } \\
\hline Colon & $73(72)$ & $33(45.2)$ & $40(54.8)$ & \multirow[t]{2}{*}{0.321} \\
\hline Rectum & $29(28)$ & $14(48.3)$ & $15(51.7)$ & \\
\hline \multicolumn{5}{|l|}{ Differentiation } \\
\hline High & $12(12)$ & $5(42.9)$ & $7(57.1)$ & \multirow[t]{3}{*}{0.461} \\
\hline Mid-low & $88(86)$ & $39(44.3)$ & $49(55.7)$ & \\
\hline Unknown & $2(2)$ & $1(50.0)$ & $1(50.0)$ & \\
\hline Positive lymph node & $49(48)$ & $26(53.6)$ & $23(46.4)$ & 0.243 \\
\hline \multicolumn{5}{|l|}{ Tumor diameters } \\
\hline$<5 \mathrm{~cm}$ & $47(46)$ & $22(46.8)$ & $25(53.2)$ & \multirow[t]{4}{*}{0.763} \\
\hline $5-8 \mathrm{~cm}$ & $31(30)$ & $15(48.4)$ & $16(51.6)$ & \\
\hline $8-10 \mathrm{~cm}$ & $14(14)$ & $6(42.2)$ & $8(57.8)$ & \\
\hline$\geq 10 \mathrm{~cm}$ & $10(10)$ & $4(37.2)$ & $6(62.8)$ & \\
\hline \multicolumn{5}{|l|}{ Vascular cancer embolus } \\
\hline Yes & $65(64)$ & $34(53.2)$ & $31(46.8)$ & \multirow[t]{2}{*}{0.382} \\
\hline No & $37(36)$ & $19(51.3)$ & $18(48.7)$ & \\
\hline
\end{tabular}


Table 4 Univariate and multivariable analysis of prognostic indicators on overall survival and disease-free survival for the prognostic significance of LRIG 1 expression of colorectal cancer patients $(\mathbf{N}=102)$

\begin{tabular}{|c|c|c|c|c|c|c|c|c|}
\hline \multirow[t]{3}{*}{ Parameters } & \multicolumn{4}{|l|}{ Overall survival } & \multicolumn{4}{|l|}{ Disease-free survival } \\
\hline & \multicolumn{2}{|l|}{ Univariate analysis } & \multicolumn{2}{|c|}{ Multivariable analysis } & \multicolumn{2}{|l|}{ Univariate analysis } & \multicolumn{2}{|c|}{ Multivariable analysis } \\
\hline & $\mathrm{HR}(95 \% \mathrm{Cl})$ & $P$ value & $\mathrm{HR}(95 \% \mathrm{Cl})$ & $P$ value & $\mathrm{HR}(95 \% \mathrm{Cl})$ & $P$ value & $\mathrm{HR}(95 \% \mathrm{Cl})$ & $P$ value \\
\hline $\begin{array}{l}\text { Age (years) } \\
(\geq 57 \text { vs }<57)\end{array}$ & $0.698(0.376-1.271)$ & 0.243 & $0.689(0.303-1.515)$ & 0.354 & $0.830(0.453-1.518)$ & 0.555 & $0.981(0.439-2.231)$ & 0.991 \\
\hline $\begin{array}{l}\text { Gender } \\
\text { (Male vs female) }\end{array}$ & $0.944(0.525-1.658)$ & 0.953 & $0.859(0.409-1.755)$ & 0.667 & $1.029(0.574-1.806)$ & 0.962 & $0.923(0.433-1.921)$ & 0.819 \\
\hline $\begin{array}{l}\text { Location } \\
\text { Rectum versus colon }\end{array}$ & $0.833(0.454-1.495)$ & 0.534 & $0.996(0.449-2.164)$ & 0.982 & $0.775(0.421-1.388)$ & 0.389 & $1.044(0.477-2.237)$ & 0.946 \\
\hline $\begin{array}{l}\text { Tumor size } \\
(\geq 5 \mathrm{~cm} \text { vs }<5 \mathrm{~cm})\end{array}$ & $0.887(0.490-1.643)$ & 0.736 & $1.099(0.512-2.310)$ & 0.837 & $0.887(0.489-1.641)$ & 0.733 & $1.054(0.471-2.311)$ & 0.928 \\
\hline $\begin{array}{l}\text { LN metastasis } \\
\text { Yes versus no }\end{array}$ & $1.073(0.588-1.923)$ & 0.855 & $0.998(0.448-2.181)$ & 0.581 & $1.091(0.604-1.965)$ & 0.787 & $0.824(0.364-1.817)$ & 0.625 \\
\hline $\begin{array}{l}\text { Vascular invasion } \\
\text { Yes versus no }\end{array}$ & $1.694(0.921-2.932)$ & 0.101 & $1.171(0.519-2.629)$ & 0.718 & $1.566(0.869-2.782)$ & 0.148 & $1.289(0.549-3.068)$ & 0.564 \\
\hline $\begin{array}{l}\text { LRIG1 expression } \\
\text { Positive versus negative }\end{array}$ & $1.252(0.690-2.260)$ & 0.473 & $1.826(0.823-4.004)$ & 0.151 & 1.077 (0.597-1.904) & 0.831 & $1.451(0.656-.081)$ & 0.271 \\
\hline
\end{tabular}

protein levels was significantly decreased in CRC tumors compared with normal control but, the high levels of leucine-rich repeats and immunoglobulin-like domains expression were not significantly associated with longer overall survival, which was consistent with the conclusion of subgroup analysis. These results suggested that the LRIG1 was not a prognostic marker in CRC tumors. Meanwhile, the LRIG1 expression was significantly lower in cancer tissues than normal ones and the same result was detected with no heterogeneity in subgroup analysis based on the type of tumor. The higher levels of LRIG1 expression was not also related to positive HPV status and tumor progression assessed by its association with degree of differentiation. Also, there was no association between the LRIG1 expression and lymphatic metastasis. Some genes, such as $K$-ras and epidermal growth factor receptor $(E G F R)$ and human epidermal growth factor receptor 2 (HER2) are reported to be involved in the progress and development of colorectal cancer [22-25], but the LRIG1 roles in colorectal cancer have not been well studied and remained contradictory.

Some studies showed that distal and proximal colon cancers differ in terms of molecular, pathological, and clinical features $[26,27]$. The present data revealed that there was not any correlation between LRIG1 expression and bilateral and peritoneal CRC metastasis $(P>0.05)$ and also with age, synchronous or metachronous CRC or primary tumor location $(P>0.05)$. Although, earlier studies proposed that LRIG1 expression was associated with a good prognosis in terms of overall survival (OS) and might act as a predictive factor for characteristics of cancer patients [28], whether the LRIG1 expression could predict a lower risk of CRC remains doubtful.

\section{Conclusions}

In conclusion, our studies revealed that although LRIG1 was down regulated in CRC and primary tumors of CRC patients but, its expression in both mRNA and protein levels, was not clinically relevant prognostic indicator in CRC. Therefore, it is suggested that LRIG1 expression analyses may not be important when making informed and individualized clinical decisions regarding the management of colorectal cancer patients.

\section{Abbreviations}

CRC: Colorectal cancer; GAPDH: Glyceraldehyde-3-phosphate dehydrogenase; LRIG1: Leucine-rich repeats and immunoglobulin-like domains 1; Ig: Immunoglobulin; PBS: Phosphate buffered saline; OS: Overall survival; DFS: Disease-free survival; PCR: Polymerase chain reaction.

\section{Acknowledgements}

The authors would like to thank all the patients who participated in this study, Dr. B.Mahjoubi and the National Institute of Genetic Engineering and Biotechnology for theirsupport.

\section{Authors' contributions}

$\mathrm{MB}$, acquisition of data and draft the work; MS, conception and designing of the work, analysis and interpretation of data, substantively revise the work; SAA, contributes to the design of the work; FM, contributes to the design of the work and data interpretation; TM, acquisition and analysis of the data. All authors read and approved the final manuscript.

\section{Funding}

None. 


\section{Availability of data and materials}

The datasets used and/or analyzed during the current study are available from the corresponding author on reasonable request.

\section{Ethics approval and consent to participate}

This study was approved by the ethics committee of National Institute of Genetic Engineering and Biotechnology (NIGEB), IRAN (\#IR. NIGEB.1395.11.10.E.). All individuals included in the study signed a consent form to use their clinical samples and personal data under the supervision of their physician.

\section{Consent for publication}

Not applicable.

\section{Competing interests}

The authors are not aware of any conflict of interest.

\section{Author details}

${ }^{1}$ Department of Cell and Molecular Biology, Faculty of Biological Sciences, Kharazmi University, Tehran, Iran. ${ }^{2}$ Department of Medical Biotechnology, National Institute of Genetic Engineering and Biotechnology (NIGEB), Tehran, Iran

Received: 24 November 2020 Accepted: 2 December 2020

Published online: 18 January 2021

\section{References}

1. Bray F, Ferlay J, Soerjomataram I, Siegel RL, Torre LA, Jemal A. Global cancer statistics 2018: GLOBOCAN estimates of incidence and mortality worldwide for 36 cancers in 185 countries. CA Cancer J Clin. 2018:68:394-424

2. Siegel R, Desantis C, Jemal A. Colorectal cancer statistics. CA Cancer J Clin. 2014:64:104-17.

3. Feng Q, Pei W, Zheng ZX, Bi JJ, Yuan XH. Clinicopathologic characteristics and prognostic factors of 63 gastric cancer patients with metachronous ovarian metastasis. Cancer Biol Med. 2013;10:86-91.

4. Sheu J, Lee CC, Hua CH, Li Cl, Lai MT, Lee SC, et al. LRIG1 modulates aggressiveness of head and neck cancers by regulating EGFR-MAPKSPHK1 signaling and extracellular matrix remodeling. Oncogene. 2014:33:1375-84

5. Lindquist D, Näsman A, Tarján M, Henriksson R, Tot T, Dalianis T, et al. Expression of LRIG1 is associated with good prognosis and human papillomavirus status in oropharyngeal cancer. Br J Cancer. 2014:110:1793-800

6. Thomasson M, Wang B, Hammarsten P, Dahlman A, Persson $J$, Josefsson $A$, et al. LRIG1 and the liar paradox in prostate cancer: a study of the expression and clinical significance of LRIG1 in prostate cancer. Int $J$ Cancer. 2011:128:2843-52.

7. Krig SR, Frietze S, Simion C, Miller JK, Fry WH, Rafidi H, et al. Lrig1 is an estrogen-regulated growth suppressor and correlates with longer relapse-free survival in ER alpha-positive breast cancer. Mol Cancer Res. 2011;9:1406-17.

8. Thompson PA, Ljuslinder I, Tsavachidis S, Brewster A, Sahin A, Hedman H, et al. Loss of LRIG1 locus increases risk of early and late relapse of stage I/ Ilbreast cancer. Cancer Res. 2014:74:2928-35.

9. Lindstrom AK, Ekman K, Stendahl U, Tot T, Henriksson R, Hedman H, et al. LRIG1 and squamous epithelial uterine cervical cancer: Correlation to prognosis, other tumor markers, sex steroid hormones, and smoking. Int J Gynecol Cancer. 2008;18:312-7.

10. Hedman H, Lindstrom AK, Tot T, Stendahl U, Henriksson R, Hellberg D. LRIG2 in contrast to LRIG1 predicts poor survival in early-stage squamous cell carcinoma of the uterine cervix. Acta Oncol. 2010;49:812-5.

11. Muller S, Lindquist $D$, Kanter $L$, Flores-Staino C, Henriksson R, Hedman $\mathrm{H}$, et al. Expression of $L \mathrm{RIG} 1$ and LRIG3 correlates with human papillomavirus status and patient survival in cervical adenocarcinoma. J Oncol. 2013:42:247-52

12. Tanemura A, Nagasawa T, Inui S, Itami S. LRIG-1 provides a novel prognostic predictor in squamous cell carcinoma of the skin: Immunohistochemical analysis for 38 cases. Dermatol Surg. 2005;31:423-30.

13. Guo D, Nilsson J, Haapasalo H, Raheem O, Bergenheim T, Hedman H, et al. Perinuclear leucine-rich repeats and immunoglobulin-like domain proteins (LRIG1-3) as prognostic indicators in astrocytic tumors. Acta Neuropathol. 2006:111:238-46.

14. Holmlund C, Haapasalo H, Yi W, Raheem O, Brannstrom T, Bragge H, et al. Cytoplasmic LRIG2 expression is associated with poor oligodendroglioma patient survival. Neuropathology. 2009;29:242-7.

15. Segatto $O$, Anastasi $S$, Alema S. Regulation of epidermal growth factor receptor signalling by inducible feedback inhibitors. J Cell Sci. 2011;124:1785-93.

16. Gur G, Rubin C, Katz M, Amit I, Citri A, Nilsson J, Amariglio N, Henriksson R, Rechavi G, Hedman H, Wides R, Yarden Y. LRIG1 restricts growth factor signaling by enhancing receptor ubiquitylation and degradation. EMBO J. 2004;23:3270-81

17. Laederich MB, Funes-Duran M, Yen L, Ingalla E, Wu X, Carraway KL 3rd, Sweeney $C$. The leucine-rich repeat protein $L R I G 1$ is a negative regulator of ErbB family receptor tyrosine kinases. J Biol Chem. 2004;279:47050-6.

18. Jensen KB, Watt FM. Single-cell expression profiling of human epidermal stem and transit-amplifying cells: Irig1 is a regulator of stem cell quiescence. Proc Natl Acad Sci USA. 2006;103:11958-63.

19. Jensen KB, Collins CA, Nascimento E, Tan DW, Frye M, Itami S, Watt FM. Lrig1 expression defines a distinct multipotent stem cell population in mammalian epidermis. Cell Stem Cell. 2009;4:427-39.

20. Powell AE. Lrig1 gastric isthmal progenitor cells restore normal gastric lineage cells during damage recovery in adult mouse stomach. Gut. 2018;67:1595-605.

21. Choi E, LantzTL, Vlacich G, Keeley TM, Samuelson LC, Coffey RJ, Goldenring JR. Lrig1+ gastric isthmal progenitor cells restore normal gastric lineage cells during damage recovery in adult mouse stomach. Gut. 2018:67:1595-605.

22. Lee WS, Jeong Heum B, Jung Nam L, Woon Kee L. Mutations in K-ras and epidermal growth factor receptor expression in Korean patients with stages III and IV colorectal Cancer. Int J Surg Pathol. 2011;19:145-51.

23. Cappuzzo F, Finocchiaro G, Rossi E, Janne PA, Carnaghi C, Calandri C, et al. EGFR FISH assay predicts for response to cetuximab in chemotherapy refractory colorectal cancer patients. Ann Oncol. 2007;19:717-23.

24. Rego RL, Foster NR, Smyrk TC, Le M, O'Connell MJ, Sargent DJ, et al. Prognostic effect of activated EGFR expression in human colon carcinomas: comparison with EGFR status. Br J Cancer. 2010;102:165-72.

25. Sawada K, Nakamura Y, Yamanaka T, Kuboki Y, Yamaguchi D, Yuki S, et al. Prognostic and predictive value of HER2 amplification in patients with metastatic colorectal Cancer. Clin Colorectal Cancer. 2018;17:198-205.

26. Missiaglia E, Jacobs B, D'Ario G, Di Narzo AF, Soneson C, Budinska E, Popovici $V$, et al. Distal and proximal colon cancers differ in terms of molecular, pathological, and clinical features. Ann Oncol. 2014;25:1995-2001.

27. Nam S, Yun S, Koh J, Kwak Y, Seo AN, Park KU, et al. BRAF, PIK3CA, and HER2 oncogenic alterations according to KRAS mutation status in advanced colorectal cancers with distant metastasis. PLoS ONE. 2016;1:e0151865

28. Zhang Q, Shi W, Wang Q, Zhu Y, Zhai C, Wang J, et al. Clinicopathological and prognostic significance of leucine-rich repeats and immunoglobulinlike domains protein 1 (LRIG1) in malignant tumors: a meta-analysis. J Cancer. 2018;9:2895-909.

\section{Publisher's Note}

Springer Nature remains neutral with regard to jurisdictional claims in published maps and institutional affiliations. 